\title{
Estudo comparativo sobre prevalência de doença periodontal em Panthera onca mantida em cativeiro e em indivíduos de natureza ${ }^{1}$
}

\author{
João Luiz R. Junior ${ }^{2 *}$, Marco A. Gioso ${ }^{2}$ e Léslie M. Domingues-Falqueiro ${ }^{3}$
}

\begin{abstract}
Rossi Jr J.L., Gioso M.A. \& Domingues-F. L.M. 2007. [A comparative study about the prevalence of periodontal disease in Panthera onca, living in captivity and in the wild.] Estudo comparativo sobre prevalência de doença periodontal em Panthera onca mantida em cativeiro e em indivíduos de natureza. Pesquisa Veterinária Brasileira 27(5):209-214. Departamento de Cirurgia da Faculdade de Medicina Veterinária e Zootecnia, Universidade de São Paulo, Av. Prof. Dr. Orlando de Marques de Paiva 87, Bloco 8-superior, Cidade Universitária, São Paulo, SP 05508-000, Brazil. E-mail: vetjrossi@gmail.com

The aim was to survey the main oral lesions related with periodontal disease of jaguars, Panthera onca, living in captivity or in the wild, as conservation of threatened animals from extinction, as in case of the jaguar, and the preservation of such species in free life may be determined by environmental conditions which can influence oral health. Forty-two jaguars (P. onca) kept in captivity in 18 institutions in the state of São Paulo were studied. The animals to be examined were anesthetized by the Plan of Neotropical Handling of Felids. Additionally, 4 jaguars (P. onca) proceeding from wild life were captured for the study on Farm Sete, municipality of Miranda, Mato Grosso do Sul, in the southern Pantanal. All animals surveyed in captivity showed various degrees of oral lesions related to periodontal disease. The animals living in the wild did not present any clinical signs of oral lesions.
\end{abstract}

INDEX TERMS: Felidae, Panthera onca, captivity animals, stomatognathic system, periodontal disease.

RESUMO.- Objetivou-se fazer levantamento das principais afeç̧ões de cavidade oral relacionadas com a doença periodontal em Panthera onca proveniente de cativeiro e natureza. Sob o ponto de vista da conservação de animais ameaçados de extinção, no caso a onça-pintada (Panthera onca), buscouse promover a orientação dos proprietários e trabalhadores rurais sobre a necessidade da preservação de tal espécie em vida livre e tentar determinar se as condições ambientais podem influenciar na saúde oral. Utilizou-se amostra constituída de 42 onças-pintadas ( $P$. onca), provenientes de 18 instituições mantenedoras de tais espécies em cativeiro no Estado de São Paulo, que foram visitadas e anestesiadas pelo Plano de Manejo de Felinos Neotropicais. Pesquisaram-se também

\footnotetext{
${ }^{1}$ Recebido em 7 de fevereiro de 2007.

Aceito para publicação em 16 de maio de 2007.

${ }^{2}$ Departamento de Cirurgia, Faculdade de Medicina Veterinária e Zootecnia (FMVZ), Universidade de São Paulo (USP). Av. Prof. Dr. Orlando de Marques de Paiva 87, Bloco 8-superior, Cidade Universitária, São Paulo, SP 05508-270, Brazil. *Autor para correspondência: vetjrossi@gmail.com

${ }^{3}$ Pós-Doutoranda do Departamento de Cirurgia, FMVZ, USP.
}

4 onças-pintadas ( $P$. onca), provenientes de vida livre, capturados na Fazenda Sete, município de Miranda, Estado do Mato Grosso do Sul, no pantanal sul mato-grossense. Todos os animais pesquisados em cativeiro apresentaram graus variados de lesões orais relacionadas à doença periodontal. Aqueles animais pesquisados na natureza não apresentaram nenhum tipo de comprometimento clínico na cavidade oral.

TERMOS DE INDEXAÇÃO: Felidae, Panthera onca, animais de cativeiro, sistema estomatognático, doença periodontal.

\section{INTRODUÇÃO}

A Panthera onca é o maior felino e maior predador terrestre do Hemisfério Oeste, encontrado somente no Novo Mundo (WCS 2002). Historicamente eram encontrados desde o sudoeste dos Estados Unidos da América até o sul da Argentina. Atualmente, é encontrada nas planícies costeiras do México até o norte da Argentina o que representa uma redução de $50 \%$ na sua área de ocupação desde o início do século XX. A onça-pintada (P.onca) é considerada uma espécie ameaçada de extinção e faz parta da lista oficial, juntamente com as 
demais espécies de felinos selvagens que ocorrem no Brasil (IBAMA 2007).

Pesquisadores brasileiros vêm relatando, através de alguns trabalhos científicos, doenças ocorridas em carnívoros selvagens bem como realizando seu tratamento (Amand \& Tinkelman 1985, Clarke \& Cameron 1997, Gioso 1998). As anormalidades da dentição e outras lesões orais podem ser resultado do desenvolvimento anormal dos tecidos, displasia ou influências do meio ambiente (Adania et al. 1998, Aguiar 1998). A alimentação oferecida pode conter níveis adequados de nutrientes, todavia a diversidade de texturas requeridas para manter a integridade dos dentes e gengivas muitas vezes não é levada em conta (Gioso 2002).

Objetivou-se fazer um levantamento das principais afecções de cavidade oral relacionadas com a doença periodontal em Panthera onca proveniente de cativeiro e natureza. Sob o ponto de vista da conservação de animais ameaçados de extinção, no caso a onça-pintada (P.onca), buscou-se promover a orientação dos proprietários e trabalhadores rurais sobre a necessidade da preservação de tal espécie em vida livre e tentar determinar se as condições ambientais podem influenciar na saúde oral.

\section{MATERIAL E MÉTODOS}

Utilizou-se amostra constituída de quarenta e duas $(\mathrm{N}=42)$ onçaspintadas (Panthera onca), provenientes de 18 instituições mantenedoras de tais espécies em cativeiro no Estado de São Paulo, que foram visitadas e anestesiadas pelo Plano de Manejo de Felinos Neotropicais. Pesquisaram-se também quatro $(\mathrm{N}=4)$ onças-pintadas (Panthera onca), provenientes de vida livre, capturados na Fazenda Sete, município de Miranda, Estado do Mato Grosso do Sul, no pantanal sul mato-grossense.

Os animais mantidos em cativeiro foram avaliados clinicamente após a realização de anestesia do tipo dissociativa (cloridrato de cetamina -Vetasetò, Fort Dodge, na dose média de $5,0 \mathrm{mg} / \mathrm{kg}$, associado a cloridrato de xilazina -RompumÒ, Bayer, na dose média de $0,1 \mathrm{mg} / \mathrm{kg}$ ). A administração foi feita por via intramuscular, por meio de dardos disparados por zarabatana. A monitorização anestésica foi realizada por meio de auscultação, para mensuração das frequiências cardíaca e respiratória.

Foram realizados os levantamentos preliminares das condições da integridade da cavidade oral através de preenchimento de odontogramas e realização de documentação fotográfica e de filmagem da cavidade oral dos animais manejados.

A partir da identificação das afecções orais, foi sugeriu-se aos técnicos e profissionais das instituições visitadas alternativas de profilaxia e tratamento dos animais.

A doença periodontal apresenta algumas variáveis como sinais clínicos, embora o fator etiológico seja a placa bacteriana. Neste projeto, pesquisou-se a presença da placa bacteriana, além de outras variáveis que compõem o quadro da doença periodontal: gengivite, exposição de furca, bolsa periodontal, retração gengival e mobilidade dental.

Não se utilizaram índices para o diagnóstico da gengivite, placa e cálculo. O diagnóstico foi realizado quando da presença destas variáveis, por meio de exame visual direto, sonda exploratória e sonda periodontal.

O trabalho com os animais de vida livre capturados na Fazenda Sete, município de Miranda-MS, no pantanal sul mato-grossense, fazia parte de uma parceria com a Universidade de Utah, EUA, o
Centro de Conservação do Pantanal, Fundação Brasileira para o Desenvolvimento Sustentável (FBDS), Wildlife Conservation Society (WCS) e a Sociedade Civil Mamirauá.

Uma vez localizado, o grande felino era imobilizado farmacologicamente por meio de anestesia dissociativa (associação de tiletamina com zolazepan: TelazolÒ -Fort Dodge, na dose média $12 \mathrm{mg} / \mathrm{kg}$, por via intramuscular), através do disparo de equipamento de anestesia remota (marcas Palmer e Dist Inject modelo 35 NÒ). A monitorização anestésica foi realizada por meio de auscultação para mensuração das freqüências cardíaca e respiratória, oximetria de pulso para aferição da saturação de oxigênio (oxímetro modelo veterinário da marca Nonin). A pressão arterial não invasiva foi monitorizada por meio de esfigmomanômetro digital da marca Omron e a temperatura corpórea por meio de ototermômetro modelo Thermoscan 6012 (Braum Kronberg).

A avaliação clínica dos animais foi realizada sob os aspectos clínicos gerais e odontológicos, através de documentação fotográfica e filmagem com câmera digital.

Após a realização dos trabalhos e recuperação anestésica, os animais foram soltos em seu ambiente natural e monitorizados quanto a sua posição com o auxílio de colares de rádio-telemetria, sendo que este aspecto não fazia parte do objetivo desta pesquisa.

Houve diferença na monitorização realizada entre os animais de cativeiro e os de vida livre devido a dificuldade de aquisição de equipamentos par utilização nos animais de cativeiro, o que somente foi possível após a aquisição de novos materiais (Auxílio Fapesp: proc. $\left.n^{\circ} 99 / 06173-5\right)$ e aprimoramento da técnica utilizada.

\section{RESULTADOS}

\section{Animais em cativeiro}

O percentual dos achados relacionados com lesões periodontais nos animais pesquisados em cativeiro é apresentado no Quadro 1 e nas Figuras 1 a 5:

Relacionando-se ainda com a doença periodontal, encontrou-se exposição de furca com prevalência de $14,28 \%$ (6 indivíduos) (Fig.4).

Observou-se retração gengival em pelo menos um dente em 14,28\% (6 indivíduos) em Panthera onca pesquisadas. A bolsa periodontal apresentou prevalência de 33,33\%, ou seja, 14 casos (Fig.5).

\section{Animais em vida livre}

Conseguiu-se realizar a captura de 4 indivíduos da espécie Panthera onca (3 fêmeas e 1 macho, todos adultos).

Ao exame físico observou-se que nenhum dos 4 indivíduos pesquisados apresentava sinais de fraturas e desgastes

Quadro I. Prevalência de lesões do periodonto de Panthera onca mantidas em cativeiro no estado de São Paulo, 2005

\begin{tabular}{lc}
\hline Enfermidade oral & $\begin{array}{c}\text { Prevalência em Panthera onca } \\
\text { (número de casos e porcentagem) }\end{array}$ \\
\hline Placa bacteriana & $3(7,0 \%)$ \\
Gengivite & $21(50,0 \%)$ \\
Cálculo dental & $42(100 \%)$ \\
Exposição de furca & $6(14,2 \%)$ \\
Retração gengival & $6(14,2 \%)$ \\
Bolsa periodontal & $14(33,3 \%)$ \\
Total de animais & 42
\end{tabular}



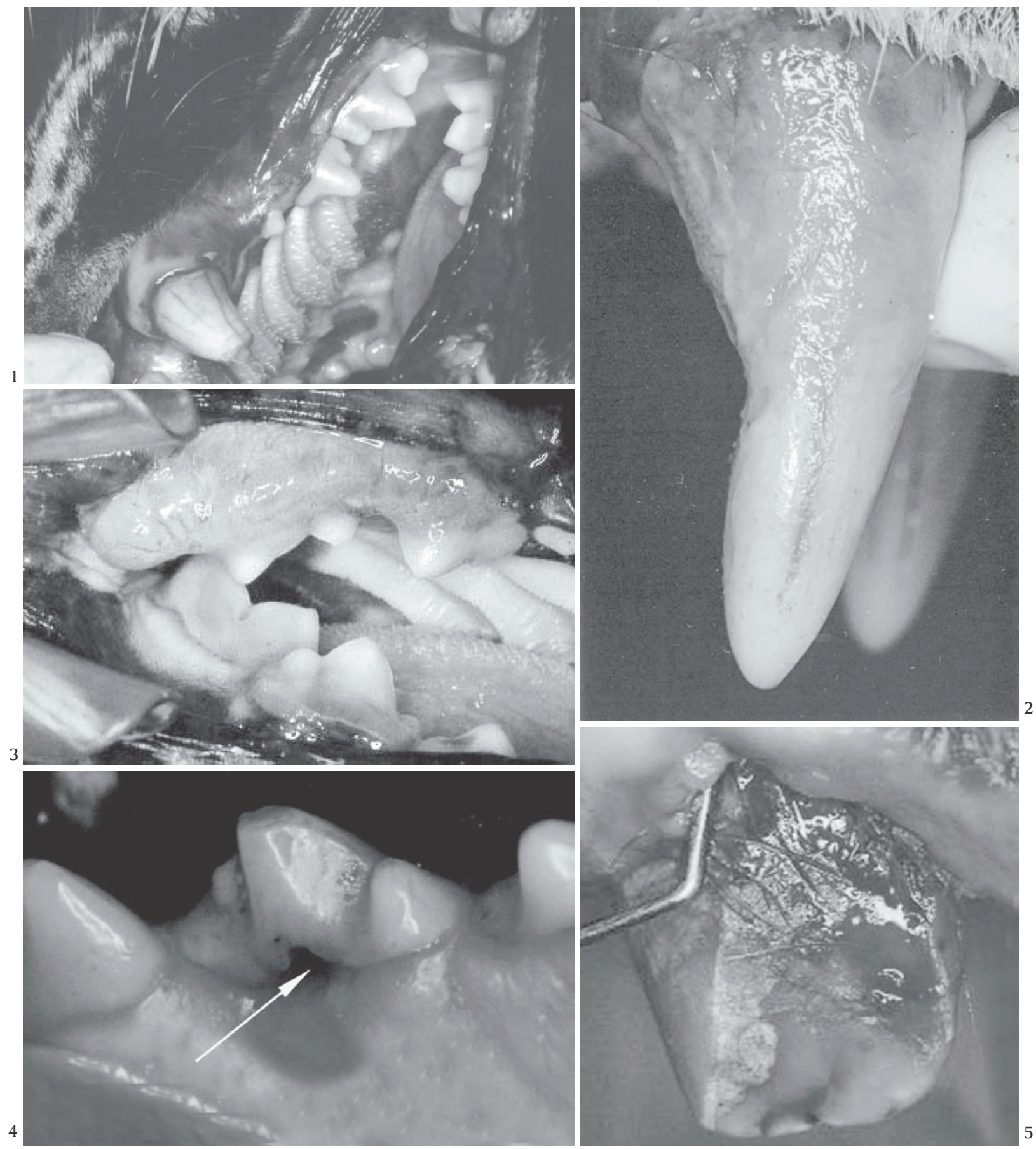

Fig.1. Gengivite Grau III em todo hemi-arco dental superior direito de Panthera onca, onde se notam eritema, edema gengival e sangramento expontâneo.

Fig.3. Aspecto de cálculo dental Grau III em Panthera onca, sobre o dente quarto pré-molar superior esquerdo, bem como demais dentes, em graus menores.

Fig.4. Aspecto da exposição de furca Grau III associada à possível lesão de reabsorção odontoclástica no dente quarto pré-molar inferior direito (seta), em Panthera onca.

Fig.2. Acúmulo de placa bacteriana Grau II no dente canino superior esquerdo, em Panthera onca.

Fig.5. Retração gengival de $4 \mathrm{~mm}$ em face vestibular do dente canino superior direito de Panthera onca, com gengivite. $\mathrm{O}$ mesmo elemento dental apresentou ainda bolsa periodontal vestibular. Nota-se ainda fratura deste elemento dental e a sondagem periodontal superior a 10 milímetros. 

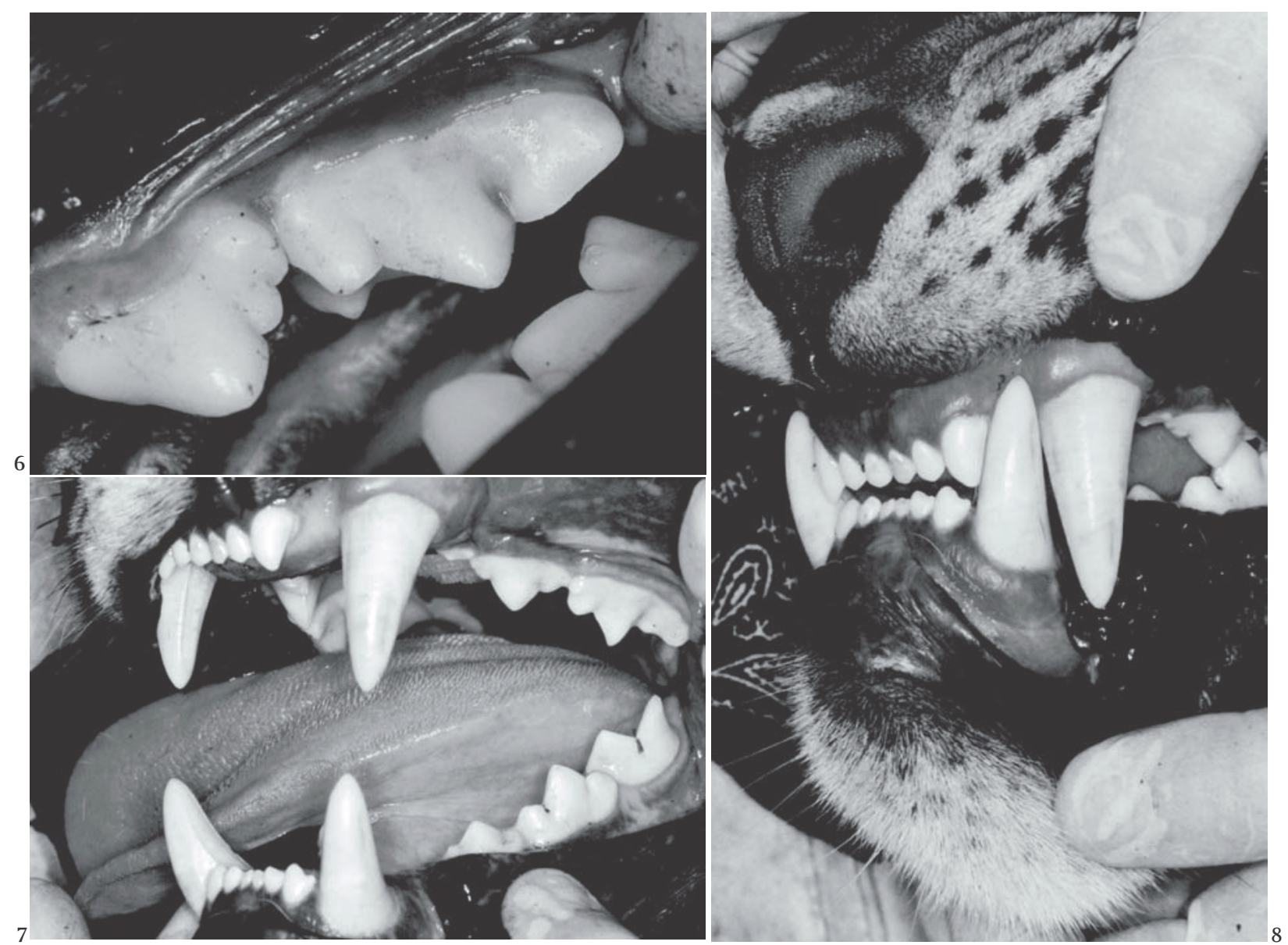

Fig.6. Aspecto dos dentes $3^{\circ}$ e $4^{\circ}$ pré-molares superiores de um indivíduo da espécie Panthera onca. Pode-se observar a ausência de gengivite e cálculo dental nestes elementos dentais.

Fig.7. Aspecto dos dentes incisivos, dentes caninos, pré-molares e molares de um indivíduo da espécie Panthera onca. Podese notar que não há presença de lesões associadas à doença periodontal ou desgaste dos dentes.

Fig.8. Aspecto dos dentes incisivos e dentes caninos de um indivíduo da espécie Panthera onca. Pode-se notar que não há presença de lesões associadas à doença periodontal ou desgaste dos dentes.

dentais. A gengivite apresentava-se discreta (Grau I), e não houve nenhum indivíduo com cálculo dental, bolsa periodontal, retração gengival, ou qualquer outro processo mórbido associado à doença periodontal.

Não se pode afirmar se os achados clínicos são pouco significativos devido aos fatores ambientais que fazem com que a cavidade oral seja próxima da higidez ou se os animais não apresentam lesões pois não atingem idade avançada e vem a óbito por causas naturais antes das manifestações clínicas (Fig.6-8).

\section{Análise estatística}

As avaliações estatísticas foram feitas com auxílio do programa Epi Info ${ }^{\mathrm{TM}}$ Version 3.3.2. O intervalo de confiança adotado foi de $95 \%$ e nível de significância $\mathrm{p}<0,05$, conforme se pode notar no Quadro 2.

Estatisticamente não houve achados clínicos nos animais capturados na natureza, desta forma apresenta-se apenas as informações referentes aos animais mantidos em cativeiro.
Quadro 2. Análise estatística de lesões na cavidade oral de Panthera onca mantidas em cativeiro no Estado de São Paulo, 2006 (Epi Info 1998, Johnson \& Leone 1974)

\begin{tabular}{lcc}
\hline $\begin{array}{c}\text { Enfermidade } \\
\text { oral }\end{array}$ & $\begin{array}{c}\text { Prevalência em } \text {. onca } \text { (número } \\
\text { de casos e porcentagem) }\end{array}$ & $\begin{array}{c}\text { Intervalo de confiança da } \\
\text { amostra pesquisada }\end{array}$ \\
\hline Placa bacteriana & $3(7,14 \%)$ & $1,8-20,55$ \\
Gengivite & $21(50 \%)$ & $34,4-65,5$ \\
Cálculo dentário & $42(100 \%)$ & $89,5-100,0$ \\
Exposição de furca & $6(14,28 \%)$ & $5,9-29,2$ \\
Retração gengival & $6(14,28 \%)$ & $5,9-29,2$ \\
Bolsa periodontal & $14(33,33 \%)$ & $20,0-49,6$ \\
Total de animais & 42 &
\end{tabular}

\section{DISCUSSÃO}

\section{Em animais de cativeiro}

Gengivite. Corroborou-se com a literatura quanto à descrição dos sinais clínicos da gengivite, já que estes sinais também foram encontrados em nesse estudo (Wiggs \& Lobprise 
1997). O diagnóstico de gengivite nos animais avaliados mostrou-se presente em Panthera onca, e como apenas foi diagnosticada esta variável nos casos presentes sem concomitância dos outros sinais de doença periodontal, a sua prevalência seria ainda maior caso fossem somadas todas as variáveis juntas (exposição de furca, bolsa periodontal, retração gengival e mobilidade). Não foi utilizado índices de gengivite pelo tempo exíguo para pesquisá-los, já que para o uso destes materiais deve haver padronização. Optou-se por pesquisar a presença ou não de várias lesões. Propõe-se que novos trabalhos possam medir índices de placa, gengivite e cálculo dental futuramente. Não foi encontrada na literatura, propostas para estes índices serem aplicados em animais desta espécie, a qual pode ser, adaptadas daquelas usadas para cães ou felinos domésticos.

Placa bacteriana. A placa bacteriana foi diferenciada de indutos moles utilizando uma seringa com água sob pressão. Ao atingir o biofilme, quando este era formado por placa bacteriana, não era possível removê-lo pois o mesmo encontrava-se aderido ao dente. Vale ressaltar que não se utilizou evidenciadores de placa bacteriana, pois o mesmo acarretaria num tempo maior de anestesia o que não era desejável. Os animais apresentaram placa bacteriana, variando a intensidade de grau 0 a III segundo a nômina adotada pelos autores consultados (Wiggs \& Lobprise 1997), mostrando a grande prevalência desta formação nos felinos selvagens estudados (Amand \& Tinkelman 1985).

Em muitos casos a placa bacteriana já havia evoluído para cálculo dental e desta forma tem-se diferenças estatísticas sobre estes achados clínicos.

Cálculo dental. Nos animais avaliados, foram encontrados cálculos nas superfícies vestibulares dos molares e prémolares superiores e inferiores assim como nas observações de realizadas por Aguiar (1998) em Didelphis albiventris (gambáde-orelhas-brancas).

Observou-se a presença de cálculo na face vestibular e lingual dos caninos superiores e inferiores; e um espécime de Panthera onca apresentou cálculos na face vestibular dos incisivos superiores e inferiores, coincidindo com os achados em gambás-de-orelhas-brancas (Aguiar 1998), embora sejam espécies distintas. A presença de cálculo dental mostrou-se bastante alta, ou seja, o intervalo de confiança de 89,56-100\%, salientando a relevância da adoção de medidas profiláticas. Não se utilizou "índices de cálculo" pelo tempo exíguo para a pesquisa.

Exposição de furca. Como apresentado nos resultados, a enfermidade foi encontrada em pequeno número (menos de $12 \%$ ) e é decorrente da retração gengival causada pela doença periodontal. Não se classificou a exposição de furca em graus. Todavia não havia referências na literatura sobre tal afecção nesta espécie para serem discutidas, e acreditase que ela siga os mesmos fenômenos descritos em felinos domésticos.

Retração gengival. Alguns espécimes apresentaram este achado clínico, embora em menos de $20 \%$ deles. Quatro espécimes de Panthera onca apresentavam retração gengival associada à bolsa periodontal, mais uma vez comprovando a alta prevalência de doença periodontal nestas espécies, o que está em conformidade com os relatos da literatura consultada (Amand \& Tinkelman 1985, Wiggs \& Lobprise 1997).

Bolsa periodontal. Alguns espécimes apresentaram bolsa periodontal profunda (maior que $6 \mathrm{~mm}$ ), com presença de secreção purulenta. Um exemplar apresentou além da bolsa periodontal abscedada uma provável fístula peri-apical com drenagem na cavidade nasal. $\mathrm{O}$ diagnóstico somente pode ser presumível, devido à falta de um equipamento de radiografia odontológico no momento da visita ao Zoológico mantenedor de tal indivíduo.

Não se obteve mensuração do "nível clínico de inserção" do epitélio juncional. Acredita-se que futuramente, projetos semelhantes aos nossos devam contemplar esta variável, já que ela parece ser a mais importante na definição de doença periodontal. Todavia a literatura consultada também não relata a medição desta variável.

\section{Em animais de vida livre}

A falta de precisão para determinar a idade dos felinos, dificultou a correlação dos achados clínicos com a cronologia etária do indivíduo. Não foi possível concluir se os animais capturados não possuem processos mórbidos orais porque são jovens ou se as condições naturais são realmente inibidoras da formação de doença periodontal, lesão de reabsorção odontoclástica felina ou outras enfermidades descritas em cativeiro nas mesmas espécies. Não há na literatura dados que permitam avaliar precisamente a idade destas espécies.

Os indivíduos em vida-livre avaliados possuíam apenas gengivite de grau I, enfermidade esta também encontrada nos animais pesquisados em cativeiro. Não se pode afirmar se a gengivite poderá evoluir e associar-se a outras manifestações clínicas da doença periodontal, uma vez que não temos como avaliar precisamente a idade dos indivíduos.

A literatura consultada afirma que a alimentação natural e a de cativeiro não influem na formação de enfermidades orais em carnívoros em cativeiro (Robinson \& Gorrel 1996, Clarke \& Cameron 1997), porém não foi possível concordar com estes autores no que diz respeito aos animais em estado natural uma vez que os mesmos sabidamente alimentam-se somente de presas naturais e não possuem doença periodontal.

\section{CONCLUSÕES}

- A prevalência é alta de lesões orais relacionadas com o periodonto em Panthera onca mantidas em cativeiro;

- A prevalência de doença periodontal é 100\% em Panthera onca;

- Os indivíduos em vida-livre não possuem os mesmos problemas na cavidade oral que os indivíduos em cativeiro.

Agradecimentos.- À FAPESP, pelo auxílio pesquisa 99/06173-5; aos tratadores, biólogos e médicos veterinários dos zoológicos e bosques municipais que participaram desta pesquisa; e ao Laboratório Bayer S/A que gentilmente doou parte dos anestésicos usados nesta pesquisa.

\section{REFERÊNCIAS}

Adania C.H., Dinis L.S.M., Silva M.G., Filoni C. \& Silva J.C.R. 1998. Avaliação 
das condições veterinárias e de manejo dos pequenos felinos neotropicais em cativeiro no Estado de São Paulo. Revta Educ. Cont. CRMV-SP 1:44-54.

Aguiar M.S. 1998. Patologias no aparelho mastigatório em Didelphis albiventris e Didelphis marsupialis (Marsupialia, Didelphimorphia, Didelphidae) do Sul do Brasil. Dissertação de Mestrado, Pontifícia Universidade Católica do Rio Grande do Sul, Porto Alegre.

Amand W.B. \& Tinkelman C.L. 1985. Oral disease in captive wild animals, p.289308. In: Harvey C.E. (ed.), Veterinary Dentistry. Mosby-Year Book, St Louis.

Clarke D.E. \& Cameron A. 1997. Dental conditions in feral Australian cats. Proc. 4th World Vet. Dental Congress, Birmingham, UK.

Epi Info, version 6. 1998. A Word-Processing, Database, and Statistics Program for Public Health on IBM, New York.

Gioso M.A. 1998. Análise morfométrica óssea e dental e sua relação com características físicas do cão (Canis familiaris) como fator predisponente para a doença periodontal. Tese de Doutorado em Cirurgia, Faculdade de Medicina Veterinária e Zootecnia, USP, São Paulo.
Gioso M.A. 2002. Odontologia para o clínico de pequenos animais. Faculdade de Medicina Veterinária e Zootecnia, USP, São Paulo. 81p.

IBAMA 2007. Lista Nacional das Espécies da Fauna Brasileira ameaçada de Extinção. Instituto Brasileiro do Meio Ambiente e dos Recursos Naturais Renováveis, Brasil. Disponível em: http:// www.mma.gov.br/port/rbf/fauna/ index.cfm. Acesso em 6 de fevereiro de 2007.

Johnson N. \& Leone F. 1974. Statistics and Experimental Design: an engineering and physical science. John Wiley, New York, p.241-244.

Robinson J.G.A. \& Gorrel C. 1996. The oral status of a pack of Foxhounds fed a "natural" diet. Proc. $4^{\text {th }}$ World Vet. Dental Congress, Birmingham, UK.

WCS 2002. All about Jaguars: ecology. Wildlife Conservation Society, New York. Disponível em: http://wcs.org/490/jag-index/jag-allabout/jagaboutecology/. Acesso em 6 de janeiro de 2007.

Wiggs R.B. \& Lobprise H.B. 1997. Exotic animal oral disease and dentistry, p.538-556. In: Idem (ed.), Veterinary Dentistry: principles and practice. Lippincott-Raven, New York. 